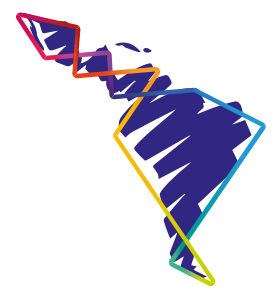

\title{
¿Huir de la guerra para encontrar la paz?
}

\section{Run away from war to find peace?}

\section{Fugir da guerra para encontrar a paz?}

\section{Dan Abner Barrera Rivera'}

\begin{abstract}
Resumen
Este artículo es la historia de vida de Vicky, una mujer nicaragüense que dejó su tierra a causa de la guerra. Los relatos expresan situaciones personales y sociales que tienen que ver con la pobreza, la explotación, la inmigración, la agresión, las rupturas familiares, la resistencia y la lucha permanente por mejores condiciones de vida en una nueva tierra. El objetivo del texto es presentar la narración de vida de una mujer extranjera desde su propia voz, desde el punto de vista de ella; aquí la "voz" del investigador solo aparece para hilvanar los hechos de la figura central que las vivió. Los acontecimientos contados develan que no solo existen fronteras geográficas, sino también culturales, laborales, sociales, educativas y emocionales, que muchas veces son infranqueables, aunque se comparta la misma casa o la mesa. La misma es una invitación para acercarnos a escuchar los saberes de una mujer inmigrante, quien ha hecho de la calle su territorio de lucha por la defensa de sus derechos humanos.
\end{abstract}

Palabras clave: historia de vida, inmigración, trabajo de campo, empleada doméstica, cuidar carros.

\begin{abstract}
Abstrac
This article deals with the life story of Vicky, a Nicaraguan woman who fled her homeland escaping war. The stories express personal and social situations pertaining to poverty, exploitation, immigration, aggression, family ruptures, resistance and the permanent fight for better living conditions in a new land. The objective of the text is to present the narration of a foreign woman's life from her own voice, from her point of view; here the "voice" of the researcher only appears to string together the facts of the central figure who lived them. The narrated events reveal the existence of not only geographical borders, but also cultural, labor, social, educational and emotional limitations, which are often impassable, even if the same house or table is shared.
\end{abstract}

1 Licenciado en Estudios Latinoamericanos; Licenciado en Teología; Máster en Derechos Humanos; realizó estudios de posgrado en Ciencias Políticas. Académico del IDELA, Universidad Nacional, Costa Rica. ORCID: https://orcid.org/0000-0003-3441-5899 
The document is an invitation to come closer and listen to the wisdom of an immigrant woman, who has made the streets her territory of struggle for the defense of her rights.

Keywords: Life story; Immigration; Field work; Domestic worker; Car watcher.

\section{Resumo}

Este artigo é a história de vida de Vicky, uma mulher nicaraguense que deixou sua terra por causa da guerra. As histórias expressam situações pessoais e sociais relacionadas à pobreza, exploração, imigração, agressão, desagregação familiar, resistência e a luta permanente por melhores condições de vida em uma nova terra. O objetivo do texto é apresentar a narração da vida de uma mulher estrangeira a partir de sua própria voz, de seu ponto de vista; aqui a "voz" do pesquisador parece apenas encadear os fatos da figura central em que viveu. Os poucos eventos revelam que não existem apenas fronteiras geográficas, mas também fronteiras culturais, trabalhistas, sociais, educacionais e emocionais, que geralmente são intransitáveis, mesmo que a mesma casa ou mesa seja compartilhada. O documento é um convite para aproximar-se a ouvir o conhecimento de uma mulher imigrante, que fez da rua seu território de luta pela defesa de seus direitos.

Palavras-chave: História de vida; Imigração; Trabalho de campo; Empregada doméstica; Cuidando de carros.

\section{Introducción}

En el presente artículo se aborda la historia de vida de una mujer nicaragüense inmigrante; se trata de un testimonio personal completo, elaborado a través de los relatos de la propia protagonista; es su voz la que se escucha. Para proceder con la construcción de los hechos pasamos por tres etapas: 1) la preparación de la historia de vida, que toma en cuenta los pasos del muestreo, el eje temático y la elaboración de la guía; 2) la realización de las entrevistas, y 3 ) tanto el análisis como la escritura de los resultados.

En las siguientes páginas, primero se hace una valoración de la importancia que tiene la historia de vida, como técnica de investigación, en las ciencias sociales y se señalan algunos aspectos metodológicos tomados en cuenta para este trabajo. Luego, se exponen los hechos relatados por la protagonista, a partir de su infancia en tierras nicaragüenses, de donde tiene que huir a causa de la guerra desatada por el Gobierno de los Estados Unidos contra Nicaragua: la citación para hacer el servicio militar es el detonante que determina su futuro. Seguidamente, se presenta el largo y azorado peregrinar de la inmigrante, quien, una vez que llega a nuevas tierras, se dispone a trabajar en cuanto oficio encuentra. Más adelante, narra algunos de los trabajos asumidos, los cuales estuvieron marcados por el irrespeto a sus derechos humanos. Al final, encuentra cierta satisfacción personal, porque ya no tiene que depender de jefes ni jefas: se dedica a cuidar los carros de los funcionarios de una universidad. 
El artículo no presenta conclusiones, no solo para evitar caer en generalizaciones basadas en casos particulares, sino porque aspira a que sean los lectores quienes hagan sus propias reflexiones respecto a la historia de vida de una mujer inmigrante que huyó de la guerra en busca de paz.

\section{La historia de vida en las ciencias sociales}

Este método cualitativo de investigación social consiste en el estudio de un individuo o familia y su experiencia de vida por buen tiempo, la cual es compartida a un investigador o también puede ser indagada en documentos y registros confiables como cartas, diarios, entrevistas, fotos, notas, entre otros (Abarca, Alpízar, Sibaja, y Rojas 2013). De acuerdo con Atkinson (1989), un relato de vida es una narración bastante completa de toda la experiencia vivida por alguien, resaltando los aspectos más importantes. Este debe ser lo más cercano posible a las palabras del entrevistado, y el investigador debe tratar de minimizar su intervención en el texto.

La construcción de la historia de vida considera el tiempo diacrónico como una continuidad lineal de los acontecimientos. Los datos están organizados en una línea del tiempo, en la que hay más secuencias que rupturas, y toma en cuenta a la persona en tanto ser social, influenciada por otras personas (familia, por ejemplo), organizaciones e instituciones, o por acontecimientos sociales o políticos mayores.

Según Mallimaci y Giménez (2009), cuando desde las ciencias sociales se acude a la historia de vida no solo es por acceder a la información que pueda proporcionar un sujeto individual, sino porque por medio de ese relato de vida, se puede ver problemáticas y temas de la sociedad: "Hablar de la vida de una persona significa mostrar las sociabilidades en las que esta persona está inserta, y que contribuye a generar con sus acciones" (p. 177). Entonces a la pregunta de en qué consiste la historia de vida, puede decirse que: "Describen los acontecimientos y las experiencias de la vida de una persona, o parte de ella, contado en sus propias palabras. Su análisis es un proceso de compaginación y de reunión de relatos, de modo que se capten los sentimientos, los modos de ver y de percibir de la persona" (Barrantes, 2016, pp. 301-302). Y también: "que se trata del relato de la vida de una persona, en el contexto determinado en que sus experiencias se desenvuelven, registrado e interpretado por un investigador o investigadora" (Mallimaci y Giménez, 2009, p. 178)

Cuando se debate sobre la selección del sujeto para la historia de vida, suele hacerse la clasificación de este en tres tipos: la "gran persona", el "marginal", y la "persona común" (Plummer, 1983). Sobre esta tipología se señalan algunas particularidades (Mallimaci y Giménez, 2009): la "gran persona" sobresale por su intervención decisiva en el desarrollo de algunos hechos históricos, identificados como tales por el 
investigador; el "marginal" es quien vive entre mundos sociales y culturales regidos por reglas diferentes, cuya experiencia de vida pone en entredicho las construcciones asumidas por la mayoría como "normales", y la "persona común" es la que rescata las voces que aparecen sumidas en generalizaciones desde otras disciplinas; desde este principio, la historia de vida permite que se escuche la voz de personas que constituyen la mayoría.

La decisión sobre quién escribir, sea un "héroe" o una "heroína", parte del entendimiento de que quien sea, ofrece elementos valiosos para el análisis; con una historia de vida no se busca una representatividad estadística. El muestreo se asienta en criterios de tipo teórico (Flick, 2007) y la persona es elegida a partir de algunos rasgos considerados relevantes en términos conceptuales. Para esta historia de vida nos interesaba que ella reuniera tres elementos: que sea una persona inmigrante, mujer y centroamericana. Con base en esa tipología mencionada, en nuestro caso se trata de una "persona común".

\section{Algunos aspectos metodológicos}

Elegimos a la señora Virginia Ruiz (Vicky), gracias a que la conocíamos desde hace algunos años por el trabajo que realizaba cerca de las instalaciones de la Universidad Nacional de Costa Rica en Heredia; ella es de nacionalidad nicaragüense, con más de treinta años de vivir en Costa Rica. Cuando le propusimos la idea de este trabajo, inmediatamente aceptó y nos dijo que estaba dispuesta a hablar de su vida como mujer inmigrante, de su experiencia y de su familia. Le explicamos por qué nos interesaba su historia de vida y cómo procederíamos para construir todo lo que ella nos compartiría; hablamos de las entrevistas y de la importancia de registrar sus relatos. Le expliqué, en mi condición de investigador, serviría de guía a través de las preguntas, para que las narraciones pudieran desarrollarse con fluidez. La colaboración entre ambos fue decisiva.

El eje temático de la narración solo se trata de un caso es la mujer inmigrante centroamericana. El objetivo de este trabajo consiste en ver desde la perspectiva de la propia protagonista el itinerario de vida que tiene una mujer inmigrante en tierras centroamericanas; aquí es central y determinante el punto de vista de ella, cuyo relato vivencial está entrelazado con los acontecimientos históricos y estos, a su vez, determinan su peregrinar.

Para la construcción de la historia de Vicky, realizamos tres entrevistas abiertas y extensas; nos valimos de una guía, pero sin estructurar un cuestionario, lo hicimos tipo agenda, así pudimos escucharle mejor y más ampliamente en sus recorridos y quehaceres por los diferentes lugares donde estuvo; se le dejó hablar sin interrumpirle 
constantemente. Las preguntas sirvieron para orientar el relato y las repreguntas para precisar detalles, ampliar información o ayudarle a que recordara o se explayara en algunos contenidos. Aunque conocíamos a Vicky desde hace algunos años, no habíamos tenido la oportunidad de conversar mucho; sin embargo, en las entrevistas, logramos tener un ambiente de confianza y respeto, en el que ella siempre estuvo distendida y segura de lo que decía. No le contó su vida a una grabadora, sino que compartió con entusiasmo sus relatos al investigador; en todo momento mostró mucha soltura e interés porque se conociera las historias que vivió en Nicaragua y Costa Rica; algunas cosas las reiteraba o le ponía más énfasis porque para ella tenían gran importancia. Para corroborar algunos datos, nos facilitó información fotocopiada. En las tres entrevistas mi papel como entrevistador e investigador siempre fue como sugieren Holstein y Gubrium (1995, p. 78), el de "abrir temas, incentivar reflexiones, sugerir interpretaciones, proponer perspectivas nuevas".

Las fechas y los lugares para realizar las entrevistas fueron negociados con la protagonista; buscamos sitios y horas con los cuales se sintiera cómoda para hablar de sí y que no perjudicaran sus horarios de trabajo. En las conversaciones ella nunca fue tan solo un sujeto que facilitó información, sino una persona que compartió su historia de vida con cordialidad y buena voluntad.

Antes de las entrevistas, le explicamos que existía la posibilidad de que este material pudiera ser publicado algún día, y sirviera para que más personas conozcan lo que vive una mujer inmigrante centroamericana en Costa Rica; le dijimos que para eso era necesario contar con su autorización. Al principio se sorprendió porque no creía que su historia de vida podría ser publicada; asintió feliz que así fuera. Me comprometí con ella a si se concretaba la posibilidad de la publicación, antes de eso, yo le leería el relato completo, para que corroborara la fidelidad de lo que ella había contado. Le consulté si quería que apareciera su nombre y apellido o prefería el anonimato; con orgullo, optó por lo primero, y dijo: "De por sí, todo lo que voy a contar es cierto". Las tres entrevistas las hicimos después de compartir algunos alimentos; la primera fue luego de que almorzamos juntos en un restaurante; las otras dos fueron tras tomar un café (Vicky dice que ella no puede vivir sin tomar café). Cada una de las entrevistas las realizamos en diferentes establecimientos de comidas, donde no hubiera ruido, fuera poco concurrido y en horarios apacibles.

Conocí a Vicky en el 2015, cuando trabajaba en los alrededores de la Universidad Nacional (UNA) en Heredia, cerca de la Facultad de Filosofía y Letras; su trabajo consistía en cuidar carros, la mayoría de ellos de los funcionarios de la UNA. Vicky tiene 52 años y vive en el barrio La Milpa, en el distrito de San Francisco de Heredia. 
A propósito del curso "Movilidad Humana y Derechos Humanos: políticas migratorias, refugiados y movilización forzosa" que impartí en el Instituto de Estudios Latinoamericanos (IDELA) de la Facultad de Filosofía y Letras de la UNA, el primer semestre de 2018, asigné como trabajo final la elaboración de un artículo que fuera resultado de la historia de vida de personas inmigrantes. Al igual que todos los estudiantes, también decidí someterme a ese ejercicio académico y este es el resultado.

\section{Una infancia sin juguetes y sin escuela}

Vicky nació en la municipalidad El Realejo, en el departamento de Chinandega que está ubicado al occidente de Nicaragua, en la frontera con Honduras. La principal actividad económica en esa municipalidad es la agricultura: siembran arroz, maíz, ajonjolí, yuca, banano, plátano y cítricos, pero lo que más se produce es la caña de azúcar. La mayor parte de los habitantes de El Realejo son pescadores y cazadores de punches (cangrejos), también extraen concha negra o cultivan camarones.

Cuenta que no tuvo infancia, porque, desde los ocho años, empezó a trabajar para ayudar a sus padres que eran muy pobres; tenía que colaborar con su mamá en todos los quehaceres de la casa; era la hija mayor de siete hermanos (tres varones y cuatro mujeres) y debía velar por ellos. De pequeña no supo lo que era tener un juguete, no registra en su memoria que alguna vez haya jugado con uno; lo que recuerda es que siempre tenía que estar pendiente de sus hermanos; además de cuidarlos, tuvo que realizar algunos trabajos fuera de casa para contribuir a la economía familiar. Dice que, desde muy niña, aprendió a conchar (sacar conchas del mar y de los manglares); vendía conchas, naranjas, limones y camarones, así como acostumbraba a comprar huesos en los mercados para revenderlos.

La evocación más fuerte que tiene de su niñez data de cuando tenía diez años, aquella vez que su mamá le regaló una mudada de ropa nueva:

Yo lo que recuerdo cuando era pequeñita que me llenó de alegría fue cuando mi mamá me llevó una falda y una blusita celestes que en la parte de adelante llevaba la figura de un pollito color amarillo; yo me puse tan contenta al ver la mudada porque nunca me habían dado nada de esas cosas. Ese fue un regalo para Navidad que mamá me dio; como ella era tan pobre, tenía que darles primero a mis hermanitos; yo le decía que prefería que les diera a mis hermanos y que yo no estrenara, yo prefería que ellos estrenaran; pero esa vez, no sé, como que alguien le regaló una plática a mi mamá, y entonces me regaló esa mudadita. Eso no lo he podido olvidar nunca.

Su mamá trabajaba en la agricultura y su papá en la pesca. Ella nunca pudo ir a la escuela porque desde niña tuvo que asumir responsabilidades de una persona mayor: 
"Cuando no estaba cuidando a mis hermanos estaba vendiendo, cuando no estaba vendiendo estaba conchando (sacando conchas), cuando no estaba sacando conchas estaba vendiendo naranjas o limones". Dice que sus padres una vez le dijeron: "Queremos ponerte a estudiar, pero por ser la hija mayor tienes que ayudarnos con el cuidado de tus hermanos".

Cuando todavía era adolescente a los trece años, conoció al joven Santos Rivera y decidió casarse con él; pensaba que así se libraría de cuidar a sus hermanos y de realizar los otros trabajos fuera de la casa para colaborar con su familia: "No era muy conveniente casarme, pero yo me casé; yo veía que era mucha responsabilidad la que yo tenía en mi casa, entonces yo pensé en mi inmadurez, verdad, que al casarme las cosas iban a cambiar, pero más bien fue peor". Su esposo era de Juigalpa del departamento de Chontales, tenía dos años más que ella. Se casaron y se fueron a vivir a Juigalpa. Al principio, la relación entre ellos fue buena, pero muchos años después, las cosas cambiaron.

Vicky dice que se equivocó al casarse porque su esposo, al igual que ella, no tenía trabajo, eso hizo que tuviera que preocuparse por conseguir algunos ingresos económicos. Consiguió ocuparse como salonera en bares y restaurantes, labor que asumió por varios años. Su primera hija (Fabiola) nació cuando tenía diecinueve años, y la segunda (Tamara) nació el año siguiente. Sonríe cuando dice que, creía que una vez casada se libraría de cuidar chiquitos (a sus hermanos), porque pronto pasó a cuidar a sus hijas.

\section{La guerra, un detonante para huir}

Desde el triunfo revolucionario del Frente Sandinista de Liberación Nacional el 19 de julio de 1979, la situación política en Nicaragua se tornó convulsa, porque el Gobierno de los Estados Unidos buscaba, por todos los medios, terminar con el Gobierno sandinista; la población vivía atemorizada por las amenazas de invasión militar. El Gobierno norteamericano (especialmente las administraciones de Ronald Reagan) desarrolló contra Nicaragua una Guerra de Baja Intensidad (GBI) y, desde 1979 hasta 1990, organizó, armó, dirigió y financió a la exguardia de la dictadura de Anastasio Somoza, denominada Contra, cuyo objetivo era desestabilizar y derrotar al Gobierno en el poder. Todos esos años hubo constantes enfrentamientos que produjeron miles de muertos y heridos en el pueblo nicaragüense. El Gobierno sandinista, con el propósito de defenderse de la guerra, porque la Contra actuaba dentro del país y en las fronteras, se veía cada vez obligado a reclutar personas, independientemente de su edad o de que fueran mujeres. Cuando Vicky recuerda esta situación dice: 
Ya a lo último no les importaba la edad, todo era que había que ser joven para ir al servicio militar; el Gobierno estaba exigiendo que la gente hiciera el servicio militar porque muchas personas habían muerto en la guerra. Al ver que había pocos varones, entonces lo que hacía el Gobierno era empezar a reclutar mujeres. En la guerra había habido siempre mujeres, pero habían sido mujeres que fueron voluntarias, ahora era obligatorio reclutarlas.

Ante tantos muertos causados por la guerra, esos fueron años difíciles para la gente, especialmente para los jóvenes, pues eran a quienes más buscaban para defender el país; eso hizo que no pocas personas trataran de salir de Nicaragua. Wilfredo, el segundo de los hermanos de Vicky, cuando llevaba un año en el servicio militar, murió en una emboscada que la Contra hizo a un grupo del ejército sandinista; lanzaron una granada y mataron a varios, entre ellos estaba Wilfredo.

Cuando el Gobierno nicaragüense enviaba la citación para que la persona se presentara a hacer el servicio militar, esta debía reportarse de inmediato, de lo contrario, al día siguiente llegaban a la casa a buscarle. Cuando Vicky recibió esa citación, ya tenía pensado no presentarse y, antes de que trataran de encontrarla, tomó la decisión de salir del país. Vicky temía la guerra y no quería morir como su hermano, por eso prefirió huir. $\mathrm{Al}$ respecto relata:

Si a uno le mandaba la cita por ejemplo para presentarse un jueves y si la persona no iba, entonces al día siguiente (viernes) a las 5:00 a. m. la policía se hacía presente en la casa de la persona, porque sabían que uno se podía escapar, que fue lo que yo hice, yo me escapé, porque era exigido hacer el servicio militar, yo le tenía miedo a la guerra.

Ella recuerda que recibió esa citación en los primeros meses de 1989, cuando acababa de cumplir 22 años.

En ese tiempo, su esposo Santos también estaba en el servicio militar y, al saber de los planes que tenía su esposa, desertó para viajar con ella. Tres décadas después de esos acontecimientos Vicky dice que: "Si hubiera estado soltera y sin hijos, tal vez no hubiera dejado Nicaragua, pero tampoco creo que hubiera sido fácil tomar una decisión, porque tenía la seguridad de que a la guerra no iría”. Ella decidió salir a escondidas rumbo a Costa Rica y no quiso que sus padres se enteraran, porque temía que se opusieran por los riesgos que significaba hacer un viaje tan largo; estuvo sin verlos por veinte años.

Contrario a lo que se suele pensar, que es el hombre quien toma las decisiones y la mujer solo obedece, en este caso fue Vicky quien propuso la idea de viajar a Costa Rica; dice que su esposo tenía miedo, pero le apoyó. Decidieron llevar a su hija 
menor que tenía dos años y a la niña mayor de tres años la dejaron con los padres de Vicky. Según ella, la citación para ir a la guerra fue lo más impactante que ha vivido, eso fue lo que determinó un cambio en su vida, de lo contrario, no hubiera dejado Nicaragua.

\section{El peregrinaje de los inmigrantes}

Decidieron viajar a pie, atravesando montañas, ríos, pueblos y ciudades. El grupo lo conformaban once personas, ocho adultos y tres niños; con ellos venía un guía, era un joven que conocía bien el camino porque ya había viajado antes. El tiempo que duró el viaje desde Chinandega, Nicaragua, hasta Los Chiles de San Carlos, en Costa Rica, fue de una semana (son $420 \mathrm{~km}$ en ómnibus). Cuando ella se refiere a los peligros que tuvieron que enfrentar en ese largo camino, dice:

La mayor dificultad era que teníamos que dormir en los montes; todos dormían, incluso mi esposo, pero yo no dormía porque me daba miedo que una culebra le picara a mi hija que tenía solo dos años; entonces lo que yo hacía era estar sentada con un pañito corriéndole a los zancudos, y siempre con miedo de que le vaya a picar una serpiente.

Conforme pasaron los días, los víveres que habían llevado (pinol, pan, azúcar, café y galletas) se acabaron; cada uno compartió lo que llevó y siempre tuvieron prioridad los niños. Ante la urgencia de conseguir dinero para comprar comida, se vieron en la necesidad de vender las únicas cosas de valor económico que llevaban: los anillos de oro de matrimonio y una cadena de oro de Vicky; la venta la hicieron en la ciudad de San Carlos en Nicaragua (cerca del Lago de Nicaragua y donde comienza el río San Juan), dice ella: "No nos dieron lo que nos costó, pero por lo menos no aguantamos hambre".

Todo el viaje lo hicieron con la preocupación de que podían ser detenidos. Cada día caminaron desde las 6:00 a. m. hasta la medianoche, con intervalos para descansar; a las doce de la noche, sin importar dónde estuvieran, se detenían para dormir. Como el guía conocía bien los trayectos, pudieron sortear todos los puestos de control policial. Al haber desacatado la orden de presentarse al servicio militar, y su esposo haber desertado del ejército, sabían que sus nombres estaban registrados y estaban siendo buscados en todas las oficinas de control de tránsito. En el camino, nunca tuvieron que pagarle a alguien para llegar a su destino y el joven que les guiaba tampoco les cobró nada, porque él también viajaba para quedarse en Costa Rica (quería evitar ser llamado al ejército), al igual que Vicky, temía perder la vida 
en la guerra. Cuando llegaron a la frontera, ingresaron por las montañas del cantón de Los Chiles de San Carlos.

\section{Los primeros trabajos en una nueva tierra}

Una vez que estuvieron en tierras costarricenses, se preocuparon por buscar trabajo:

Lo primero que hice en Costa Rica fue ir a arrancar yuca, había un plantío de yuca y nos dijeron que ahí nos podían dar trabajo, y nosotros nos fuimos a pedir trabajo, pagaban doce mil colones la semana, entonces así fue como nosotros empezamos a trabajar, pero no teníamos dónde estar; pasamos cuatro semanas debajo de un palo de mango. Después una señora me mandó a llamar y me dijo que ella tenía un lugar que le llamaban la quesera (donde hacían queso), entonces desocuparon la quesera para que nosotros vivamos ahí, mi esposo la chiquita y yo, nadie más. Otra gente les dio apoyo a los demás del grupo. Ahí nos disolvimos como grupo.

En Los Chiles, trabajaron en el campo cuatro años, ahí había fincas que ocupaban peones; además de arrancar yuca, sembraban y cosechaban frijoles, ñampí y tiquisque; laboraban de lunes a sábado, de 7:00 a. m. a 4:00 p. m. En esos primeros años siempre tuvieron que llevar a su hija con ellos porque no conocían una persona de confianza con quién dejarla; la ponían debajo de algún arbolito y de rato en rato la miraban y le daban sus alimentos.

De Los Chiles pasaron a la comunidad de Estanquillos en el cantón de Atenas, ahí trabajaron cogiendo café por cuatro años y dormían en la misma finca cafetalera; su esposo laboraba como jornalero, estaba encargado de chapear, fumigar y echar tanto los pesticidas como los plaguicidas al cafetal. En Estanquillos conocieron a una señora que les ayudó con la niña: "Después una vecina nos dijo que se la diéramos que ella la iba a cuidar mientras trabajábamos, y mi hija empezó a ir a la escuela también”.

\section{El trabajo de empleada doméstica}

En esos años, Vicky conoció a un señor nicaragüense quien le sugirió que se fueran a Heredia, pues ahí podían encontrar trabajos menos duros y mejor pagados. Cuando llegó allí, el primer trabajo que tuvo fue de empleada doméstica con dormida dentro; debía cuidar a un adulto mayor de 78 años. Para esa fecha ya había tenido problemas con su esposo y había decidió separarse; su hija seguía en la escuela, pero se quedaba en la casa de una amiga de Vicky.

En ese nuevo trabajo, además de hacer todos los quehaceres de la casa (limpiar, lavar, planchar, cocinar) tenía que atender al adulto mayor, que sufría de Alzheimer; cuenta que fue una experiencia bastante dura: "Porque el señor se levantaba a toda 
hora en las noches, gritaba, llamaba a la policía y decía que le estaban pegando, cosa que no era cierto; pero se entiende que era por su enfermedad". Trabajó en esa casa por dos años y dice que, al no saber ella leer ni escribir, tuvo muchas limitaciones, dado que no podía enterarse de algunas cosas que estaban escritas o no podía tomar nota cuando recibía algunos encargos de personas que llamaban por teléfono. En cada casa que trabajó, antes de empezar siempre les dijo a los dueños (jefes o jefas de hogar) que ella no sabía leer ni escribir, pero para ellos eso no era un problema y fueron comprensivos, siempre le dijeron que a "Ellos no les importaba que no supiera leer con tal que haga bien las cosas de la casa”.

Por esas limitaciones tuvo algunas dificultades cuando trabajó en la atención al adulto mayor, porque debía seguir indicaciones para la aplicación de sus medicinas. Relata que los hijos del señor (eran cuatro, todos profesionales), que no vivián con él, le dejaban las instrucciones con algunas imágenes, para que pudiera identificar mejor las horas. Aunque nunca llevó cursos de primeros auxilios o de enfermería, sabía inyectar, poner suero y sacar sangre; todo eso lo aprendió al ver cómo lo habían hecho otras personas en Nicaragua y Costa Rica. Los hijos del adulto mayor le tenían confianza y siempre aceptaron que fuera ella quien le aplicara las inyecciones, le pusiera el suero y le sacara sangre. Al señor tenían que ponerle inyecciones cada dos semanas; colocarle el suero con frecuencia (de día o de noche) y llevarle al hospital para extraerle sangre, pero, por sus condiciones de su salud, no podían trasladarlo, por eso Vicky era la encargada de sacarle las muestras. Cuenta ella que, actualmente, en su casa en La Milpa de Heredia, la gente le busca para que les inyecte, dice: "No estoy autorizada, pero la gente confía en mí. Y también he aprendido a atender partos, y lo he hecho varias veces".

Cuando falleció el adulto mayor, ella se quedó sin trabajo, pero pronto la llamaron para que laborara como empleada doméstica con dormida dentro, con una familia en Santo Domingo de Heredia; cree que esta fue una experiencia muy dura:

En esa casa yo sufrí mucho, yo lloraba en esa casa; la señora me trataba muy feo, palabras feas me decía, y las comidas no las podía tomar recién hechas, tenía que comer las comidas con ocho o quince días de guardadas en la refrigeradora, llegó al extremo de darme comidas en mal estado.

Esa familia estaba conformada por tres adultos: la dueña de la casa, su hija, el yerno y dos nietos; el trato que le daban era muy duro:

todos eran iguales, me maltrataban mucho de palabras, yo era la empleada, pero como vivía ahí entonces tenía que estar disponible a cualquier hora para hacer lo que ellos dijeran; no tenía días libres y no respetaban mis horas de descanso, a veces, 
a las once o doce de la noche me tocaban la puerta para que les prepare un batido o porque habían traído a sus amistades.

\section{El trabajo de cuidar carros}

De esa casa la sacó su amigo nicaragüense Máximo, quien un día al pasar por ahí, la vio llorando. Le propuso que fuera a ayudarle a cuidar carros en los alrededores de la UNA y trabajó con él por cuatro años y medio, hasta que se aprobó la reforma a la Ley de Tránsito a mediados del 2017, que sanciona a quienes estacionan frente a un hidrante, en las esquinas, en las aceras o en zona con línea amarilla. Los alrededores de la UNA donde ellos cuidaban los carros, fue señalizada en su totalidad con línea amarilla, entonces se vieron obligados a buscar trabajo en otro lugar. Máximo encontró un nuevo sitio para cuidar carros a $1 \mathrm{~km}$ de distancia de la universidad y doña Vicky se posicionó a dos cuadras de la UNA, encontró una calle ancha sin líneas amarillas. Quienes parquean sus carros ahí son los mismos funcionarios de la UNA que antes dejaban sus carros en los alrededores de la institución. Cuando acordamos hacer estas entrevistas, Vicky ya llevaba más de dos años en ese lugar. Fue por iniciativa de ella que ese nuevo territorio le "pertenece", ese es su espacio laboral. Cuenta que, cuando empezó a trabajar, los primeros días se le acercó un señor que cuidaba carros en una calle paralela y le advirtió que ese territorio le pertenecía y si quería trabajar ahí debía pagarle siete mil colones por día. A ella no le dio temor y tampoco le dio importancia, señala: "Hasta el día de hoy no le he pagado nada".

Vicky expresa que desde que llegó a Costa Rica, este es el trabajo donde más satisfecha se ha sentido:

Cuidar carros ha sido en el que mejor me he sentido porque aquí no tengo jefe ni jefa que me dé órdenes, grite o controle, yo soy mi propia jefa; en los otros trabajos me estresaba porque debía cumplir con las exigencias que por lo general me hacían de mala manera, ahora solo estoy pendiente de los carros.

En todos los trabajos, ha recibido un trato parecido: poco respeto, escaso reconocimiento, abuso en los pagos y muchas exigencias. Cuando laboró en la casa del adulto mayor, pasó algunas veces hasta dos meses sin salir de allí, porque tenía que estar pendiente del señor en todo, y nunca le pagaron más por esa dedicación. En ningún trabajo ha tenido aguinaldo, seguro social ni vacaciones y, cuando alguna vez reclamó algo, de una vez la amenazaban con despedirle o sencillamente la despedían.

\section{Tan cerca y tan lejos de la universidad}


Lo que más le agrada de cuidar carros ahora es saber que son de funcionarios de la universidad, a quienes conoce desde hace varios años y son personas que le tratan con respeto y cariño: "iLlegan y me dice: doña Vicky ahí le dejo el carrito! Es tanta la confianza que me tienen que a veces me dejan las llaves del carro, porque tal vez el carro está mal acomodado, o por si la alarma se activa, entonces yo tengo la llave". En caso de que el carro esté mal acomodado, ella espera que venga alguien conocido de la universidad y le pide que le ayude a acomodarlo. Hechos como estos han pasado varias veces y no ha habido problemas.

Aunque la relación que tiene con los profesores dueños de los carros es cordial y respetuosa, no ha trascendido a más, todo se limita al saludo; ve que llegan a prisa y se van igual. Una vez que suben a sus carros, la mayoría le dice "Dios le bendiga doña Vicky", pero nadie se ha preocupado por saber más de ella. Cuando algunos le han preguntado dónde vive y se enteran de que habita en La Milpa de Heredia, no vuelven a preguntarle más nada. Tampoco alguien le ha preguntado por qué trabaja cuidando carros. Piensa que nadie se imagina todas las veces que tuvo que dormir debajo de los palos de mango para llegar a Costa Rica, la cantidad de kilómetros que tuvo que caminar o todos los trabajos que tuvo que realizar, pero dice: "Yo me siento muy orgullosa de estar en Costa Rica, pasé muchas cosas, pero aquí estoy". Nadie sabe que no pudo ir a la escuela y que no aprendió a leer ni a escribir; cree que, aunque los profesores le tienen confianza y por eso traen sus carros para que los cuide; sin embargo, no existe la confianza para que se conozcan más.

Vicky trabaja de lunes a viernes, empieza a las 6:00 a. m. y se queda hasta muy tarde, a veces hasta las 10:00 p. m., porque algunos profesores llegan a esa ahora a recoger el carro. No tiene una tarifa (precio) de cobro por hora, como hacen otras personas que trabajan cuidando carros en la vía pública o como sucede en los parqueos privados donde el costo promedio por hora es mil doscientos colones. Independientemente de las horas que esté parqueado el carro, la mayoría de los dueños le dan mil colones. Ella resalta lo siguiente:

Solo hay uno que se llama Ángel, que me da tres mil colones, es el que más me da, y el que menos me da es quinientos colones. A veces yo digo qué injusto, deberían de pagarme por lo menos un "rojito" (mil colones) porque les he cuidado el carro todo el día; pero yo digo que Dios los bendiga, nada más.

Cuenta que uno de los mayores riesgos que tiene ese trabajo es que se roben un carro. Recuerda un caso que sucedió no hace mucho, cuando observó que un joven que no era dueño del carro iba con una llave para abrirlo; ella lo siguió y se interpuso entre la puerta del carro y él, y le arrancó la llave de la mano. Supuestamente, era el novio de una profesora de la universidad, pero ella no lo conocía. Con firmeza 
le dijo: "Ese carro no sale sin la autorización de la dueña". El tipo se asustó cuando ella le quitó las llaves y le dijo que iba a llamar a la policía; el joven se tuvo que ir sin las llaves. Más tarde, apareció la dueña, y ella le dijo "Vea: ¿por qué me hace usted eso de mandar una persona a llevar el carro sin avisarme? Cuando usted parqueó el carro, no me dijo que otra persona se lo iba a llevar". La profesora se disculpó y le dijo que había pelado con el novio, por eso él vino a llevarse el carro.

Dice que se esmera mucho en cuidar lo que no es de ella y, en todos estos años (siete en total), no ha tenido problemas, nunca han golpeado o dañado un solo carro; siempre está lista con su celular para tomar foto de la placa de algún otro carro si comete una infracción, y luego entregársela al dueño del vehículo afectado para que verifique quién es el propietario, pero, hasta ahora no ha tenido necesidad de hacer eso. Dice que, si vinieran los ladrones a robar un carro, lo único que ella puede hacer es llamar a la autoridad, por eso tiene a mano los números telefónicos de la policía.

Por día, cuida aproximadamente trece carros:

La gente piensa que nosotros los que cuidamos carros nos estamos haciendo de plata, pero no es así, porque como hay gente que da quinientos, hay gente que da mil, también hay gente que no da nada, y eso la gente que no está acá no lo ve; uno lo que gana es para sobrevivir, al menos yo lo que gano es para mi casa y para ayudar a mis papás; lo más que saco por día son quince rojitos, es poquito, pero es preferible eso antes que estar de balde. Hay muchos que se montan en su carro a las cinco de la tarde, y se van sin pagar, y el carro ha estado parqueado ahí desde las 7:00 a. m., o dicen: no ando plata. Ese es el trabajito de uno, iqué puede hacer uno!

Nunca ha estado vinculada a ninguna organización social, religiosa ni política. Las amistades más cercanas aparte de sus familiares (sus dos hijas y dos nietos) son las vecinas de La Milpa y unas señoras que viven en la calle donde cuida los carros.

Cuenta que a veces le salen trabajos extra los fines de semana; algunos sábados va a limpiarle la casa a un señor:

Voy una vez al mes, el señor es muy bueno, es muy consciente, llego a las 8:00 a.m. hasta las 4:00 p. m. y me da veinte mil colones, me da el desayuno, me da el almuerzo, me da cafecito, me viene a dejar y me viene a llevar cuando voy a trabajar también; es un trabajo que resulta mejor que cuidar carro; si a mí me salieran esos trabajos todos los fines de semana yo lo haría con mucho gusto, porque a mí me gusta trabajar.

Sus vacaciones son a mitad del año o a finales; son obligadas, porque la UNA tiene receso en esos periodos, por eso no hay carros para cuidar. Ella aprovecha esos días para viajar a Nicaragua y visitar a sus padres, si no puede viajar en julio, lo hace en 
diciembre. Sus progenitores están mayores, el señor tiene setenta y ocho años y la señora setenta y dos; ha querido traerlos para que conozcan Costa Rica, pero ellos no quieren venir.

Como las condiciones climáticas en Costa Rica son muy variadas, ella está preparada para trabajar en la época seca y lluviosa, además de traer su termo con café, botella de agua y el almuerzo en un táper, siempre tiene a mano la sombrilla, botas, capa, palo (bastón), foco (para cuando se va la luz), chaleco fosforescente y su silbato (pito). Dice que este último es muy útil porque le ayuda para poner orden desde lejos:

Me sirve para pitar cuando llega alguien y sepa que uno le está viendo cuando se está parqueando, porque si no le dicen a uno, yo no la vi. Si yo estoy ocupada sacando un carro, entonces alguien llega y cree que yo no le estoy viendo, entonces yo le pito para que vea que yo le estoy viendo.

Cuando hace mucho sol, se pone a la sombra de un arbolito de guayaba; también tiene una silla para descansar y se distrae tanto con los videos como con la música de su celular; le gustaría leer algo, pero no puede, porque no sabe. Comenta que, "Si tuviera la oportunidad de aprender a leer y a escribir lo haría porque es lo que más deseo, para no depender de mis hijas, que tienen que leerme los mensajes que algunas personas me envían por WhatsApp". Por el trabajo que realiza y la ayuda de sus hijas, ha aprendido a reconocer los números y el valor de las monedas y de los billetes.

No tiene un seguro médico y, aunque se siente bien de salud, padece de dolor de cabeza, pero dice que, "Con dolor de cabeza o sin él, nunca dejó de cuidar carros todos los días". Hace varios años, tuvo un seguro privado, pero la situación económica se le complicó y dejó de pagar.

Ahora que cuida carros y ve todos los días que mujeres y hombres de diferentes edades manejan carro, le gustaría aprender a manejar, pero le da un poco de miedo. El proyecto personal que tiene es arreglar su casa en La Milpa, para traer algún día a sus padres y llevarlos a pasear a varios lugares de Costa Rica.

Sus hijas viven en Costa Rica; Tamara, la menor, trabaja como miscelánea en una empresa y estudia en las noches, está casada con un nicaragüense y tienen dos hijos. Fabiola, la hija mayor, trabaja como empleada doméstica; sus tres hijos viven con el papá en Nicaragua. Vicky dice que, al principio, extrañaba su país, pero ahora ya se acostumbró a vivir en Costa Rica. Lo que le molesta es el trato irrespetuoso que algunos costarricenses tienen hacia los nicaragüenses; cuando ella escucha algunas de esas ofensas, les dice: "Disculpe, que Dios le bendiga; o sea, yo no los maltrato 
ni les ofendo; usted sabe que nosotros los nicaragüenses trabajamos, y yo no les digo nada más".

Al final de las entrevistas, expresó que estaba muy agradecida con la gente que le aprecia y le confía el cuidado de sus carros; reiteró que es una mujer muy trabajadora y que lucha todos los días para que no le falte la comida.

\section{Referencias}

Abarca, A., Alpízar, F., Sibaja, G., y Rojas, C. (2013). Técnicas cualitativas de investigación. San José, Costa Rica: Editorial UCR.

Atkinson, R. (1998). The Life Story Interview. Qualitative Research Method Series, núm. 44. Londres: Sage.

Barrantes, R. (2016). Investigación: Un camino al conocimiento. Un enfoque cualitativo, cuantitativo y mixto. San José, Costa Rica: EUNED.

Flick, U. (2007). Introducción a la investigación cualitativa. Madrid: Ediciones Morata.

Holstein, J. y Gubrium, J. (1995). The Active Interview. Qualitative Research Methods Series, vol. 37. Londres: Sage.

Mallimaci, F. y Giménez, V. (2009). Historia de vida y métodos biográficos. En Vasilachis, I. (coord.). Estrategias de investigación cualitativa, (pp. 175-212). Barcelona: Gedisa Editorial.

Plummer, K. (1983). Documents of Life. An Introduction to the Problems and Literature of a Humanistic Method. Londres: Allen \& Unwin.

Tognonato, C. (2003). Tornando a casa. Conversazioni con Franco Ferrarotti. Roma: Edizioni Associate.

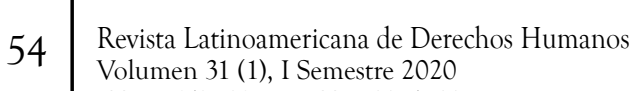

ISSN: $1659-4304 \cdot$ EISSN: $2215-4221$ 